Note

\section{Compositional Change of Refractory Elements in Solution during Aging in High Cr Heat Resistant Ferritic Steels}

\author{
Y. MURATA, K. KAWAMURA, ${ }^{1)}$ M. KAMIYA, ${ }^{2)}$ \\ M. MORINAGA, R. HASHIZUME, ${ }^{3)} \mathrm{K}$. MIKI, ${ }^{4}$ ) \\ T. AZUMA ${ }^{4)}$ and T. ISHIGURO ${ }^{4)}$
}

Department of Materials Science and Engineering, Graduate School of Engineering, Nagoya University.

1) Graduate Student of Nagoya University, now at NKK Corp.

2) Graduate Student of Nagoya University, now at Aisin AW Co. Ltd.

3) Technical Research Center, The Kansai Electric Power Co. Inc.

4) Muroran Laboratory, The Japan Steel Works, Ltd.

(Received on May 22, 2002; accepted in final form on August 29, 2002)

\section{Introduction}

The improvement in the creep strength has been achieved by the addition of boron as well as refractory elements, Mo and $\mathrm{W}^{1-3)}$ in high $\mathrm{Cr}$ heat resistant ferritic steels. It has been accepted that the improvement by the refractory elements originates mainly in the solid-solution hardening of steels. In those steels containing a comparatively large amount of the refractory elements, on the other hand, the creep strength is improved by the presence of fine coherent precipitates of intermatallic compounds due to the precipitation hardening in them. ${ }^{4)}$ However, in the steels containing an excess amount of refractory elements, in particular, $\mathrm{W}$, it is known that the creep strength in a long time becomes lower than the values extrapolated from the creep strength in a short-time.

Recently, it has been found that Re is an effective element for improving a long-time creep-strength of high $\mathrm{Cr}$ ferritic steels. ${ }^{5-7)}$ This is in contrast to the effect of $\mathrm{W}$ on the ferritic steels. As mentioned above, it is important to investigate the solid solubility limit of refractory elements in the matrix when considering the creep strength of high $\mathrm{Cr}$ ferritic steels. This is usually obtained indirectly by the thermodynamic calculation based on the chemical composition as well as the weight of the extracted residue from the steels, ${ }^{8,9)}$ so that some errors are included inevitably in the calculated values. Then instead of such an indirect method, a direct analyzing method is employed in this study. In this method, the amount of refractory elements dissolved in the matrix is analyzed directly by means of the ICP emission spectrochemical analysis of the electrolyte which is prepared by electrolyzing the matrix phase in the steel, as explained later.

\section{Experimental Procedure}

\subsection{Steel Preparation}

Seven ferritic steels have been used in this study. The chemical compositions are listed in mass \% units in Table 1. Of these steels, both A and B steels contain $4 \% \mathrm{~W}$, and their chemical compositions are similar to each other except for Re. B steel contains $0.2 \% \mathrm{Re}$, but A steel contains no Re. $1 \% \mathrm{~W}$ of A steel is replaced by $1 \% \mathrm{Re}$ in $\mathrm{C}$ steel, so this $\mathrm{C}$ steel contains $3 \% \mathrm{~W}$ and $1 \% \mathrm{Re}$. Also, Mo and $\mathrm{V}$ compositions are modified slightly in $\mathrm{C}$ steel.
Table 1. Chemical compositions of steels used in this study, $\operatorname{mass} \%$.

(a) \begin{tabular}{|c|c|c|c|c|c|c|c|c|c|c|c|c|}
\hline Steel & $\mathrm{C}$ & $\mathrm{Cr}$ & $\mathbb{H}_{0}$ & $\mathrm{~V}$ & $\mathrm{Nb}$ & $\mathbb{W}$ & $\mathrm{Co}_{0}$ & $\mathrm{Re}$ & $\mathrm{Fe}$ & $\overline{\mathrm{Md}}$ & Mo+H+Re/mass\% & Mo+M+Re/mol\% \\
\hline \hline $\mathrm{A}$ & 0.09 & 10.1 & 0.01 & 0.19 & 0.06 & 4.0 & 3.0 & 0.0 & bal. & 0.854 & 4.0 & 1.24 \\
\hline B & 0.09 & 10.2 & 0.01 & 0.19 & 0.06 & 4.0 & 3.0 & 0.2 & bal. & 0.858 & 4.2 & 1.31 \\
\hline C & 0.10 & 10.1 & 0.10 & 0.15 & 0.06 & 3.0 & 3.0 & 1.0 & bal. & 0.855 & 4.1 & 1.30 \\
\hline
\end{tabular}

(b) \begin{tabular}{|c|c|c|c|c|c|c|c|c|c|c|c|c|}
\hline Steel & $\mathrm{C}$ & $\mathrm{Cr}$ & $\mathrm{M}_{0}$ & $\mathrm{~V}$ & $\mathrm{Nb}$ & $\mathrm{N}$ & $\mathrm{Co}$ & $\mathrm{Re}$ & $\mathrm{Fe}$ & $\overline{\mathrm{Md}}$ & Mo+H+Re/mass\% & MotM+Re/mol\% \\
\hline
\end{tabular}

\begin{tabular}{|c|c|c|c|c|c|c|c|c|c|c|c|c|}
\hline \hline$D$ & 0.11 & 11.2 & 0.40 & 0.20 & 0.08 & 1.9 & 3.0 & 0.3 & bal. & 0.855 & 2.6 & 0.91 \\
\hline E & 0.11 & 11.2 & 0.40 & 0.20 & 0.08 & 1.9 & 3.0 & 0.6 & bal. & 0.855 & 2.9 & 0.99 \\
\hline F & 0.11 & 11.1 & 0.40 & 0.20 & 0.08 & 2.0 & 3.1 & 0.9 & bal. & 0.856 & 3.2 & 1.10 \\
\hline$G$ & 0.11 & 11.1 & 0.10 & 0.20 & 0.08 & 1.9 & 3.0 & 1.7 & bal. & 0.856 & 3.7 & 1.16 \\
\hline
\end{tabular}

$\mathrm{D}, \mathrm{E}, \mathrm{F}$ and $\mathrm{G}$ steels listed in Table 1(b) contain about $2 \% \mathrm{~W}$, and the Re compositions are changed systematically in these four steels. Here, $G$ steel contains the largest amount of Re among the four steels, and its Mo composition is lowered slightly in order to suppress $\delta$ ferrite formation in it. The chemical compositions of these experimental steels are controlled using the d electrons parameter, $\overline{\mathrm{Md}}$, in order to suppress the formation of the $\delta$ ferrite phase in them. The critical $\overline{\mathrm{Md}}$, value for suppressing the $\delta$ ferrite formation is about 0.862 for steels containing $3 \% \mathrm{Co}^{4}{ }^{4}$ The $\overline{\mathrm{Md}}$, parameters listed in Table 1 are much lower than this critical value. In accordance with this prediction, no $\delta$ ferrite is formed in any steel.

The $50 \mathrm{~kg}$ ingots of these seven steels were prepared by vacuum induction melting, and then processed by hot forging in a conventional way. The slab size was $35 \mathrm{~mm}$ thick, $130 \mathrm{~mm}$ wide and $1000 \mathrm{~mm}$ long. In order to control the grain size, each slab was normalized at $1373 \mathrm{~K}$ for $18 \mathrm{ks}$ (5h), followed by annealing at $993 \mathrm{~K}$ for $72 \mathrm{ks}(20 \mathrm{~h})$. Subsequently, they were austenitized at $1343 \mathrm{~K}$ for $18 \mathrm{ks}$ $(5 \mathrm{~h})$ followed by quenching and then tempered first at $843 \mathrm{~K}$ for $72 \mathrm{ks}(20 \mathrm{~h})$ and secondly at $953 \mathrm{~K}$ for $72 \mathrm{ks}$ $(20 \mathrm{~h})$ for the quality heat treatment. The heating rate was controlled to be $5.56 \times 10^{-3} \mathrm{~K} \mathrm{~s}^{-1}(20 \mathrm{~K} / \mathrm{h})$, whereas the cooling rates were controlled to be $2.78 \times 10^{-2} \mathrm{~K} \mathrm{~s}^{-1}(100 \mathrm{~K} / \mathrm{h})$ for quenching and $1.39 \times 10^{-2} \mathrm{~K} \mathrm{~s}^{-1}(50 \mathrm{~K} / \mathrm{h})$ for tempering, respectively. These rates were set for a simulation of the thermal hysteresis which appears in the central part of a large-scaled rotor. After tempering, every steel has been supplied for the creep rupture test at $923 \mathrm{~K}$.

\subsection{ICP Emission Spectrochemical Analysis}

Specimens taken from the grip part of test pieces crept at $923 \mathrm{~K}$ have been electrolyzed using a $10 \%$ hydrochloric acid-methanol solution under a constant-potential. ${ }^{10)}$ It is known that $\mathrm{MC}$ carbide, ${ }^{11)} \mathrm{M}_{23} \mathrm{C}_{6}$ carbide $^{10)}$ and the Laves phase $^{10)}$ are extracted effectively by using this solution. In fact, $\mathrm{MX}$ carbonitride, $\mathrm{M}_{23} \mathrm{C}_{6}$ carbide and the Laves phase have been observed in an extraction replica made by using this solution.

In order to remove the extracted residues, the electrolyte has been first passed through a membrane filter having $0.2 \mu \mathrm{m}$ pores, and then a membrane filter having $0.025 \mu \mathrm{m}$ pores. In general, a filtering using a membrane filter having $0.2 \mu \mathrm{m}$ pores is enough to remove fine precipitates such as MX, BN, etc. from the electrolyte. ${ }^{12)}$ In fact, the amount of the extracted residues after the first-step filtering does not change after the second-step filtering in this study. To make sure, however, the two-steps filtering has been adopted to remove the precipitates thoroughly from the electrolyte.

Since organic solvents are not suitable for the ICP emission spectrochemical analysis, the filtered electrolyte has been diluted by distilled water so that the total content of organic solvents becomes less than $5 \%$. Then this diluted electrolyte has been supplied for the ICP emission spectrochemical analysis. In order to obtain calibration curves for 
the ICP analysis, two kinds of aqueous solutions have been used as the standard solutions. One is a $1 \mathrm{ppm}$ solution of Mo, $\mathrm{W}$ or $\mathrm{Re}$, and the other is a $5 \mathrm{ppm}$ solution. The calibration curve for each element has been obtained by the least square fit using three data, that is, $0 \mathrm{ppm}$ (distilled water), $1 \mathrm{ppm}$ and $5 \mathrm{ppm}$ standard values.

\section{Results and Discussion}

\subsection{Contents of Refractory Elements in the Matrix of High W Containing Steels}

The results of the ICP emission spectrochemical analysis are shown in Fig. 1 for A and B steels and in Fig. 2 for C steel. In these figures, the vertical axis shows the analyzed value in mass $\%$, and the abscissa shows the aging time at $923 \mathrm{~K}$. Here, "zero" of the aging time corresponds to the as-tempered state. In the bar charts, gray, white and black show the respective contents to $\mathrm{W}, \mathrm{Re}$ and Mo, respectively. Also, line graphs exhibit the amount of extracted residues. Here, the analyzed data is represented in the mass $\%$ units in these figures, because it is obtained in the mass \% units directly from the ICP emission spectrochemical analysis.

It is seen from Fig. 1 that the total amount of the refractory elements in the matrix of A and B steels is about 1.2 and $1.4 \%$, respectively, in the as-tempered state. It decreases with increasing aging time in both steels. For example, it is $0.95 \%$ in A steel aged for $26.11 \mathrm{Ms}(7253 \mathrm{~h})$ and $0.85 \%$ in B steel aged for $30.33 \mathrm{Ms}(8425 \mathrm{~h})$. The matrix of B steel contains about $0.2 \% \mathrm{Re}$ after aging for $30.33 \mathrm{Ms}$ (8425 h). Interestingly, this corresponds to the Re composition in the steel and is similar to the content of Re dissolving in the matrix in the as-tempered state. This result indicates that almost all the alloyed Re remains in the matrix phase of B steel even after aging. Therefore, the observed decrease in the total amount of the refractory elements is attributable mainly to the decrease in the $\mathrm{W}$ content in $\mathrm{B}$ steel. For example, the $\mathrm{W}$ content in the matrix decreases from $1.2 \%$ in the as-tempered state to $0.65 \%$ in the aged state for $30.33 \mathrm{Ms}(8425 \mathrm{~h})$.

As shown in Fig. 1, the $\mathrm{W}$ content in the matrix of $\mathrm{A}$ steel decreases monotonously from $1.25 \%$ in the as-tempered state to $0.8 \%$ in the aged state for $39.72 \mathrm{Ms}(11033$ h). For advanced high $\mathrm{Cr}$ ferritic steels the contents of Mo and $\mathrm{W}$ in the matrix after a long time creep test at $923 \mathrm{~K}$ have been investigated by analyzing the chemical compositions of the extracted residues. ${ }^{13)}$ It has been shown that the solubility of $\mathrm{Mo}+(1 / 2) \mathrm{W}$ in those ferritic steels is $0.5-0.8$ mass\%. Also, by using Atom-Probe-Field-Ion-Microscopy (APFIM), the contents of Mo and $\mathrm{W}$ in the matrix have been measured to be 0.26 mass $\%$ and 0.82 mass $\%$, respectively. ${ }^{14)}$ As explained before, the result of A steel obtained from this study is about $0.8 \%$, which is consistent with the previous reports.

In contrast to such a decrease in the matrix content of the refractory elements by aging, the amount of extracted residues increases in both $\mathrm{A}$ and $\mathrm{B}$ steels in the beginning of aging, and then it is saturated to be about $8 \%$.

Figure 2 shows the results on $\mathrm{C}$ steel, in which $1 \% \mathrm{~W}$ in A steel is replaced by Re. The total amount of refractory elements in the matrix is $2.7 \%$ in the as-tempered state of this steel, and it decreases with aging time, resulting in $1.5 \%$ after aging for $25.77 \mathrm{Ms}(7159 \mathrm{~h})$. This value of $1.5 \%$ is still much higher than that in A or B steel after aging (Fig. 1). This is caused simply by a high Re content in the matrix, i.e., $1.0 \%$ in the as-tempered state, $0.8 \%$ after aging for $16.02 \mathrm{Ms}(4449 \mathrm{~h})$ and $0.65 \%$ after aging for $25.77 \mathrm{Ms}(7159 \mathrm{~h})$, as shown in Fig. 2 . In contrast to the Re content, the $\mathrm{W}$ content in the matrix of $\mathrm{C}$ steel decreases considerably. For example, it changes from $1.6 \%$ in the astempered state to $0.75 \%$ after aging for $25.77 \mathrm{Ms}(7159 \mathrm{~h})$. As a result, the dissolved $\mathrm{W}$ content becomes comparable to the Re content in the aged steel, although the W composition is three times higher than the Re composition in $\mathrm{C}$ steel (see Table 1). Thus, it can be said that Re has a larger solubility in steel than $\mathrm{W}$.

The amount of the extracted residues in $\mathrm{C}$ steel also increases with increasing aging time and it is saturated to be about $6.5 \%$. This value is slightly lower than the saturated values, about $0.8 \%$, observed in both $\mathrm{A}$ and $\mathrm{B}$ steels (see Fig. 1). This is consistent with the result that the total amount of the refractory elements dissolved in the matrix of C steel is larger than that of A or B steel.

\subsection{Change in the Dissolved Re Content in the Matrix with Re Composition in Steels}

Figures 3 and 4 show the results of ICP emission spectrochemical analysis on the (b) group steels, D, E, F and G
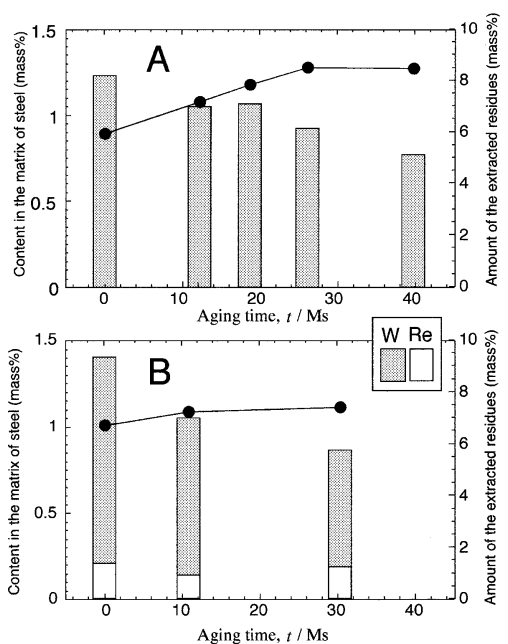

Fig. 1. Results of ICP emission spectrochemical analysis on electrolyte obtained by electrolyzing A and B steels. Bar charts show the content of refractory elements, and line graphs show the amount of extraction residues.

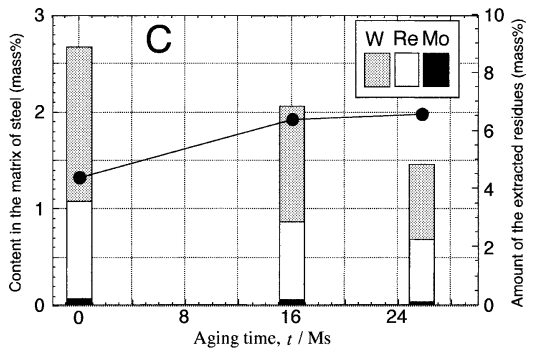

Fig. 2. Results of ICP emission spectrochemical analysis on electrolyte obtained by electrolyzing $\mathrm{C}$ steel. Bar charts show the content of refractory elements, and line graphs show the amount of extraction residues.
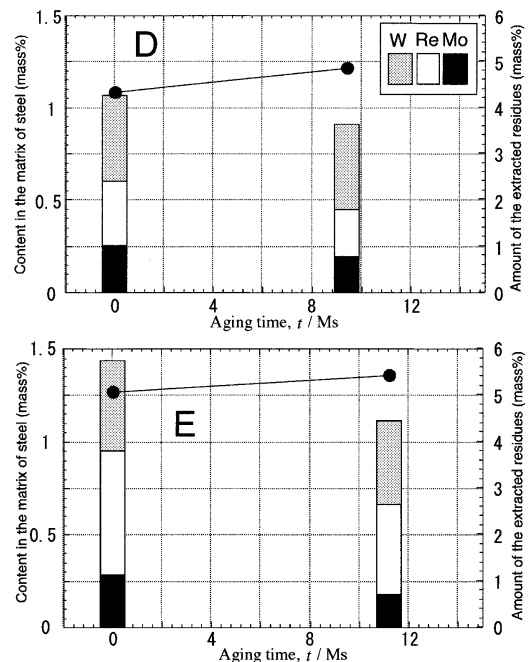

Fig. 3. Results of ICP emission spectrochemical analysis on electrolyte obtained by electrolyzing $\mathrm{D}$ and $\mathrm{E}$ steels. Bar charts show the content of refractory elements, and line graphs show the amount of extraction residues. 

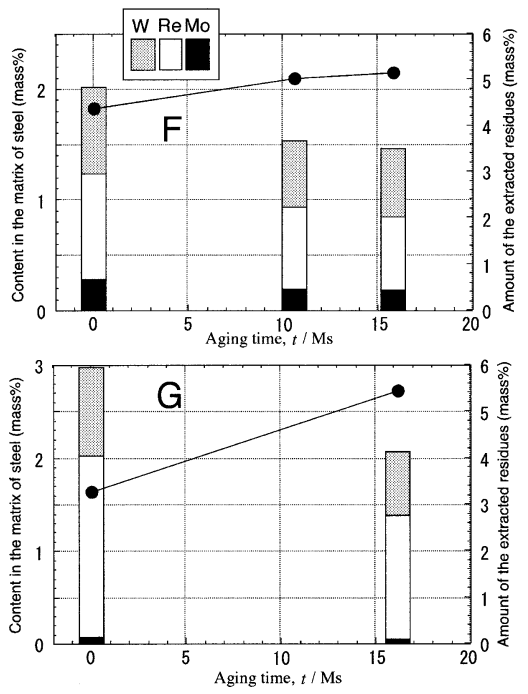

Fig. 4. Results of ICP emission spectrochemical analysis on electrolyte obtained by electrolyzing $F$ and $G$ steels. Bar charts show the content of refractory elements, and line graphs show the amount of extraction residues.

shown in Table 1. In these steels, the Re composition is changed systematically from 0.3 to $1.7 \%$ but the $\mathrm{W}$ composition is kept constant, about $2 \%$. Furthermore, these steels except for $\mathrm{G}$ contain $0.4 \% \mathrm{Mo}$, which is higher than the Mo composition in the (a) group steels, A, B and C. As a result, the amount of Mo in the matrix becomes larger in these steels as shown in Figs. 3 and 4 compared with that in the steels shown in Figs. 1 and 2. It is found that the amount of refractory elements in the matrix of the four steels in the astempered state increases with increasing Re composition listed in Table 1(b). For example, it is $1.1 \%$ in D containing $0.3 \%$ Re and $3.0 \%$ in $\mathrm{G}$ containing $1.7 \%$ Re. In C, D, E, F and $\mathrm{G}$ steels, $\mathrm{Re}$ content in the matrix decreases slightly with increasing the aging time. It is considered that Re precipitates as the Laves phase in these steels. In fact, it is reported that the amount of the Laves phase increases during creep in high $\mathrm{Cr}$ ferritic steels. ${ }^{15)}$

The saturated values of the extracted residues in the four steels, D, E, F and G, range from 4.5 to $5.5 \%$, and these values are lower than those in the three steels, A, B and C. This is because those four steels contain a smaller amount of $\mathrm{Mo}+\mathrm{W}+\mathrm{Re}$ than the three steels, as shown in Table 1 .

Since the aged samples are taken from the grip part of the crept specimens as mentioned in the Sec. 2.2, each sample differs in the aging time. Then the total amount of the refractory elements is not always compared among the aged samples, but it seems to increase with increasing Re composition in the steel. For example, it is $0.9 \%$ in $\mathrm{D}$ aged for $9.43 \mathrm{Ms}(2620 \mathrm{~h})$ and $2.1 \%$ in $\mathrm{G}$ aged for $16.19 \mathrm{Ms}$ $(4497 \mathrm{~h})$. This result is consistent with the result obtained in $\mathrm{C}$ steel, in which the increase of the total amount is caused by the increase of the dissolved Re content in the matrix. In fact, as shown in Figs. 3 and 4, the dissolved Re content in the matrix observed in the aged specimen is about $0.5 \%$ in $\mathrm{E}$ steel containing $0.6 \% \mathrm{Re}$, and about $1.35 \%$ in $\mathrm{G}$ steel containing $1.7 \%$ Re.

It is found that the Re content becomes larger than the $\mathrm{W}$ content in the matrix when the steel contains more than $0.6 \% \mathrm{Re}$. This is similar to the case of $\mathrm{C}$ steel. In the case of $\mathrm{E}, \mathrm{F}$ and $\mathrm{G}$ steels, the Re composition in the steel is lower than the $\mathrm{W}$ composition, but the Re content in the matrix are higher than the $\mathrm{W}$ content. This fact indicates directly that the solubility limit of $\mathrm{Re}$ in high $\mathrm{Cr}$ ferritic steels is much larger than that of W. This is also understood by the binary phase diagrams of $\mathrm{Fe}-\mathrm{W}$ and $\mathrm{Fe}-\mathrm{Re}$ systems, since they show a much larger solubility limit of Re than $\mathrm{W}$ in Fe. ${ }^{16)}$

\section{Conclusions}

A method for the direct analysis of the electrolyte have been adopted to analyze the amount of refractory elements, $\mathrm{W}, \mathrm{Re}$ and Mo, dissolved in the matrix of high $\mathrm{Cr}$ and $\mathrm{Re}-$ containing heat resistant steels, and its change with aging time at $923 \mathrm{~K}$ has been investigated systematically. The results obtained are as follows;

(1) The total amount of the refractory elements in matrix in the steel with $4 \% \mathrm{~W}$ is about $2 \%$ in the as-tempered state when the steel contains no Re. This amount keeps decreasing with increasing aging time and finally reaches to about $0.95 \%$.

(2) When the steel contains Re, the total amount of refractory elements in the matrix increases with increasing Re composition in the steel in both the as-tempered state and the aged state. For example, it is about $1.5 \%$ even after aging for $25.77 \mathrm{Ms}(7159 \mathrm{~h})$ when the steel contains $1 \% \mathrm{Re}$ substituting $1 \% \mathrm{~W}$.

(3) Such a large amount of the refractory elements in the Re containing steels is attributable to the large solid solubility of $\mathrm{Re}$ in high $\mathrm{Cr}$ ferritic steels.

\section{Acknowledgement}

This work is supported in part by the Grant-in-Aid for Scientific Research of Japan Society for the Promotion of Science (JSPS), Japan.

\section{REFERENCES}

1) T. Fujita: Tetsu-to-Hagané, 76 (1990), 1053.

2) H. Naoi, M. Ogami, Y. Hasegawa, H. Mimura and T. Fujita: Advanced Heat Resistant Steels for Power Generation, ed. by R. Viswanathan and J. Nutting, Institute of Materials, London, (1999), 259.

3) K. Hidaka, Y. Fukui, S. Nakamura, R. Kaneko, Y. Tanaka and T. Fujita: Advanced Heat Resistant Steels for Power Generation, ed. by R. Viswanathan and J. Nutting, Institute of Materials, London, (1999), 418.

4) Y. Murata, K. Takami, M. Kamiya, M. Morinaga, R. Hashizume, T. Azuma, Y. Tanaka and T. Ishiguro: Tetsu-to-Hagané, 88 (2002), 214.

5) M. Morinaga, R. Hashizume and Y. Murata: Materials for Advanced Power Engineering 1994, ed. by D. Coutsouradis et al., Kluwer Academic Publishers, Dordrecht, (1994), 319.

6) Y. Tsuda, M. Yamada, R. Ishii and O. Watanabe: Advances in Turbine Materials, Design and Manufacturing, ed. by A. Strang et $a l$., The Institute of Materials, London, (1997), 283.

7) F. Masuyama and N. Komai; Materials for Advanced Power Engineering 1998, ed. by J. Lecomte-Beckers et al., Forchungszentrum Jülich GmbH, Jülich, Germany, (1998), 269.

8) R. Ishii, Y. Tsuda, M. Yamada and M. Miyazaki: Advanced Heat Resistant Steels for Power Generation, ed. by R. Viswanathan and J. Nutting, Institute of Materials, London, (1999), 259.

9) Y. Kadoya, R. Umakoshi, H. Kawai and T. Tsuchiyama: Report of the 123rd Committee of Japan Society for the Promotion of Science, 43 (2002), 23.

10) H. Kutsumi, A. Chino and Y. Ishibashi: Tetsu-to-Hagané. 78 (1992), 594.

11) Y. Murata, K. Suga and N. Yukawa: J. Mater. Sci., 21 (1986), 3653.

12) F. Kurosawa, I. Taguchi, M. Tanino and R. Matsumoto: J. Jpn. Inst. Met., 45 (1981), 63.

13) Y. Kadoya and E. Shimizu: Report of the 123rd Committee of Japan Society for the Promotion of Science, 42 (2001), 127.

14) M. Hätterstrand, M. Schwind and H.-O. Ardren: Materials for Advanced Power Engineering 1998, ed. by J. Lecomte-Beckers et al., Forchungszentrum Jülich GmbH, Jülich, Germany, (1998), 529.

15) Y. Kadoya, B. F. Dyson and M. McLean: Materials for Advanced Power Engineering 1998, ed. by J. Lecomte-Beckers et al., Forchungszentrum Jülich GmbH, Jülich, Germany, (1998), 593.

16) H. Okamoto: Phase Diagrams for Binary Alloys, ASM International, Materials Park, OH, (2000), 372. 